\title{
The new Algerian Digital Seismic Network (ADSN): towards an earthquake early-warning system
}

\author{
A. Yelles-Chaouche, T. Allili, A. Alili, W. Messemen, H. Beldjoudi, F. Semmane, A. Kherroubi, H. Djellit, Y. Larbes, \\ S. Haned, A. Deramchi, A. Amrani, A. Chouiref, F. Chaoui, K. Khellaf, and C. Nait Sidi Said \\ CRAAG Centre de Recherche en Astronomie Astrophysique et Geophysique, Route de l'observatoire BP63 Bouzaréah Alger, \\ Algérie
}

Correspondence to: A. Yelles-Chaouche (a.yelles@ craag.dz)

Received: 4 June 2013 - Revised: 26 August 2013 - Accepted: 6 September 2013 - Published: 23 October 2013

\begin{abstract}
Seismic monitoring in Algeria has seen great changes since the Boumerdes earthquake of 21 May 2003. Indeed, the installation of a new digital seismic network has resulted in a significant upgrade of the previous analog telemetry network.

During the last four years, the number of stations in operation has increased substantially from 25 to 69 , and 20 of these are broadband, 2 are very broadband, 47 are short period. 21 are equipped with accelerometers. They are all managed by Antelope software from Kinemetrics (US Cie), and they are all connected in real time and use various modes of transmission (e.g., satellite, internet, mobile phone). The spatial repartition of the stations now cover most of northern Algeria. In addition, 70 GPS stations have recently been added to this seismological network, most of them collocated with the seismological stations.

Since the installation of the network, the records of local or distant events have improved significantly. The automatic processing of the data in a few minutes allows alert messages to be distributed to Civil Defense and other national authorities to react promptly to any emergency. The current strategy is to improve the data quality, to increase the density of the network by adding about 50 new stations, to reduce the processing time, and to reduce the time needed to send out an alert message. The result should be greatly improved network performance, which will lead to an effective earlywarning system.
\end{abstract}

\section{Introduction}

Northern Algeria lies along the Eurasian-African tectonic boundary. In contrast to other Mediterranean areas (e.g., Italy, Greece, Turkey), Algeria is generally marked by moderate rather than strong seismic activity (Fig. 1) (Benhallou, 1985; Yelles-Chaouche et al., 2006). However, major events do happen, and they are capable of causing significant damage in urban centres. Among the more significant past events, we can list those affecting Algiers in 1365 and 1716, the Oran event of 1790, the Blida event of 1825 , and the seismic events of El Asnam on 10 October 1980 (Ms: 7.3) and Boumerdes on 21 May 2003 (Mw: 6.8). To manage and study such seismic activity, appropriate equipment and skilled staff are required.

Developments in seismological technology, in terms of sensors, digitizers, and communication networks, have led to the installation of new alert systems in several countries as Japan (Nakamura, 1996), USA (Allen, 2007), Turkey (Erdik et al., 2003). The purpose of these systems is to provide, as quickly as possible, the first parameters of the event, to rapidly inform the decision makers for crisis management, and to enable strategic infrastructure to be safeguarded, such as nuclear power plants and railways.

The catastrophic effects of the Boumerdes event of 21 May 2003 (Mw: 6.8), which resulted in 2263 fatalities and a cost of 5 billion USD, highlighted the need to develop and install such an alert system in Algeria.

The new Algerian seismic network called Algerian Digital Seismic Network (ADSN, Yelles-Chaouche et al., 2007) has been in operation since 2009. Its first objective was to install a rapid alert system to diffuse informations to authorities and 


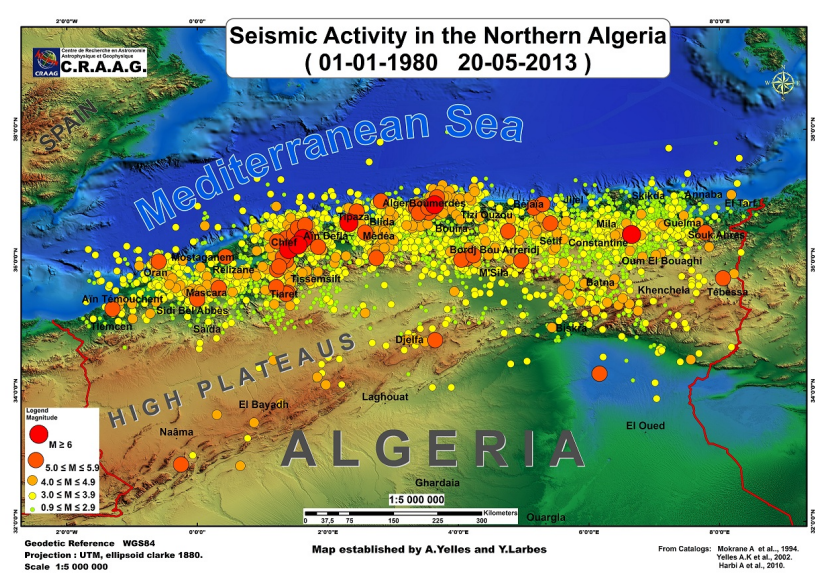

Fig. 1. Seismic Activity in the Northern Algeria (from 1 January 1980 to 20 May 2013).

the population. In addition, it has a role to develop seismological studies in the different regions of Algeria. The second objective now is to install sufficient numbers of new seismological stations so that the territory will be covered more densely, to improve data transmission, and to establish an early warning system.

\section{History of the Algerian seismological network}

In Algeria, the seismological instrumental period started in 1910 when the first seismological station was installed at Algiers, or more precisely, at the Bouzareah Observatory (Roussel, 1973). This station was equipped with a mechanical Bosch-Mainka seismograph. Later on, other seismic stations with short-period Grenet-Coulomb seismographs were installed in different regions of northern Algeria in dams such as the Oued-Fodda (El-Asnam) station, installed in 1935, and the Benaouda (Relizane) station, installed in 1955 or in the city of Setif in 1958 (Mokrane et al., 1994). The installation of these stations marked the beginning of research activity in seismology in Algeria.

In the 1950s, several Algerian seismic catalogues were published (Hee, 1950; Rothé, 1950; Glangeaud, 1954), and they reviewed the most important Algerian earthquakes since 1716.

The sparsely distributed stations described above continued in operation more or less continuously until 1980 when the El Asnam earthquake occurred (Benhallou, 1985).The network at that time was unable to correctly record or locate this major earthquake, nor could it adequately keep track of the ensuing aftershock activity. This major event demonstrated, therefore, the urgent need to install a real-time seismic network with more stations.

In 1985, CRAAG (Centre de Recherche en Astronomie Astrophysique et Géophysique) obtained financial support to develop seismic monitoring in Algeria by modernizing the seismic network. Thirty-two seismological stations were acquired in 1988, and they were installed in 1990 after selecting appropriate sites. The data recorded by this seismic network were transmitted by radio waves (telemetry).

Shortly after the network was established, the political situation in Algeria deteriorated. From 1992 to 1998, most of the stations were damaged or totally destroyed. In 1998, only four regional stations remained active.

In 1998 the political environment started to improve, and the Algerian seismic network was progressively reinstalled. The network of about 25 stations was split into four subnetworks (Algiers, Oran, Constantine, Chleff) (Yelles et al., 2003). Following the Boumerdes earthquake of 21 May 2003 , the system was updated with a new broadband digital seismological network. Today, with a total of 69 seismic stations of several types, the seismological network in Algeria (Fig. 2) is now in a position to perform as an early warning system.

\section{The new Algerian Digital Seismic Network: instrumentation and spatial distribution}

The installation of the new seismic network in Algeria went through several phases. The first, in 2006, started with the cooperation of CEA, the Chinese Earthquake Administration. Indeed, after the Boumerdes earthquake, China offered CRAAG a digital network of 10 broadband stations, a portable network of 10 short-period stations, and scientific assistance. Within 18 months, this new network was installed and ready to go into operation (Yelles et al., 2007). At the same time, several engineers from CRAAG received training in China. During this period, CRAAG acquired from Kinemetrics (US Cie) its own equipment composed of about 60 new stations.

In 2009, the second phase of the project involved the progressive installation of the new CRAAG equipment. This phase went through several steps: site surveying and site selection, construction of the sites, deciding which type of communication to use and finally, installation of the seismic equipment. In the last four years, the number of stations in operation has increased significantly (Fig. 2). There is now a total of 69 stations, 20 of which are broadband (Fig. 2a, b), 2 very broadband (Fig. 2c), 47 short period (Fig. 2d). 21 are equipped with accelerometers. The last Broad Band Station was installed recently on 20 August 2013 in the region of Tikjda (Great Kabylie, central part of Algeria). Data are sent in real time using various modes of transmission, and they are managed by Antelope software (Fig. 2e). The stations cover most of northern Algeria (Fig. 2). Because of the high seismic risk in the Tellian region, a denser network of stations was installed there, mainly around the seismogenic basins where the main cities of Algeria are localized (Oran, El-Asnam, Algiers, Tizi Ouzou, etc.). 

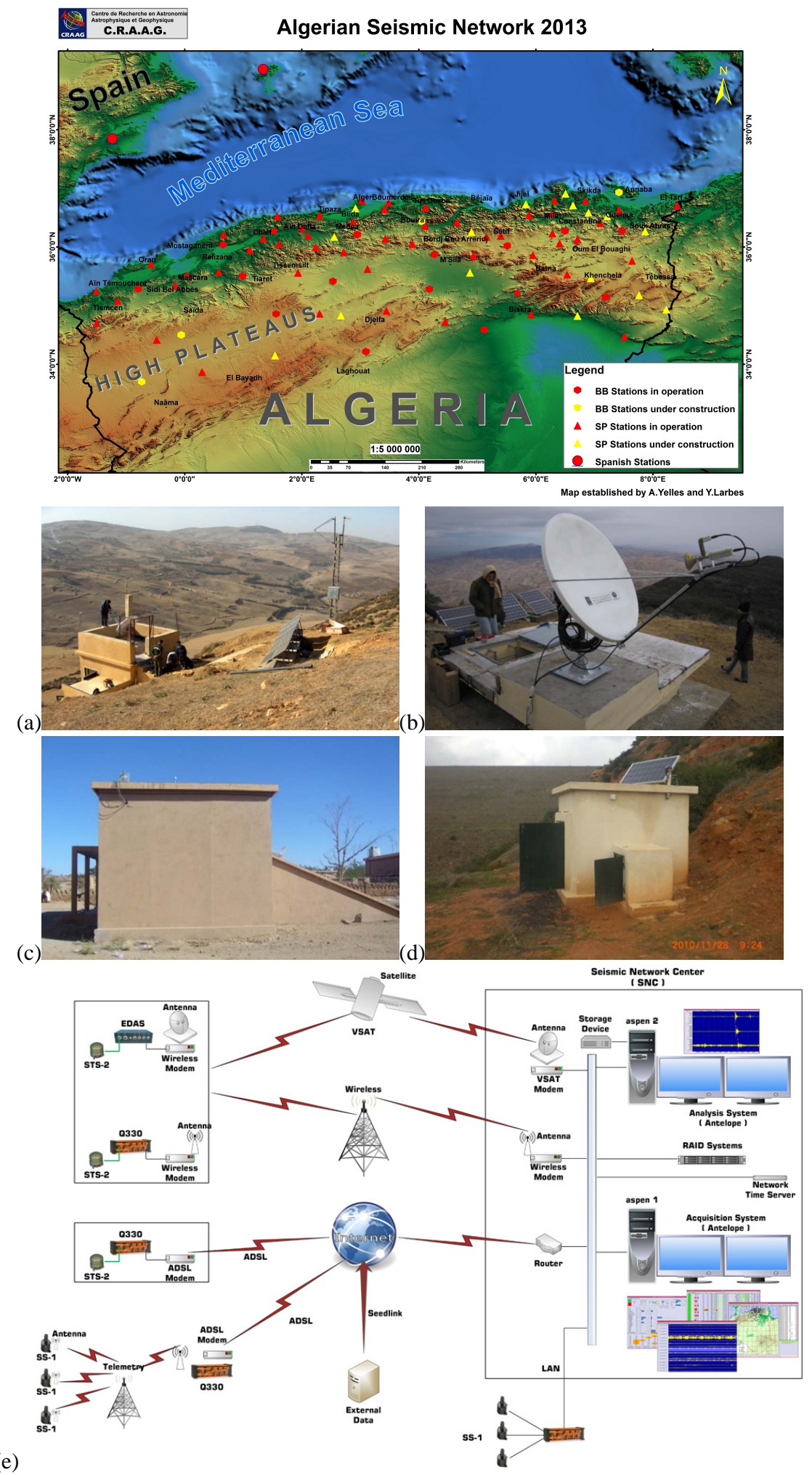

Fig. 2. The Algerian Digital Seismic Network in 2013. (a) Broad Band station (Mahouada, Algiers Network). (b) Broad Band station (Tessala, Oran network). (c) Very Broad Band station (Tamanrasset Observatory). (d) Short Period Station (Keddara dam, Algiers network). (e) Near Real-time data acquisition process. From data acquisition in the station to the reception in the Seismic Center of the Network. 

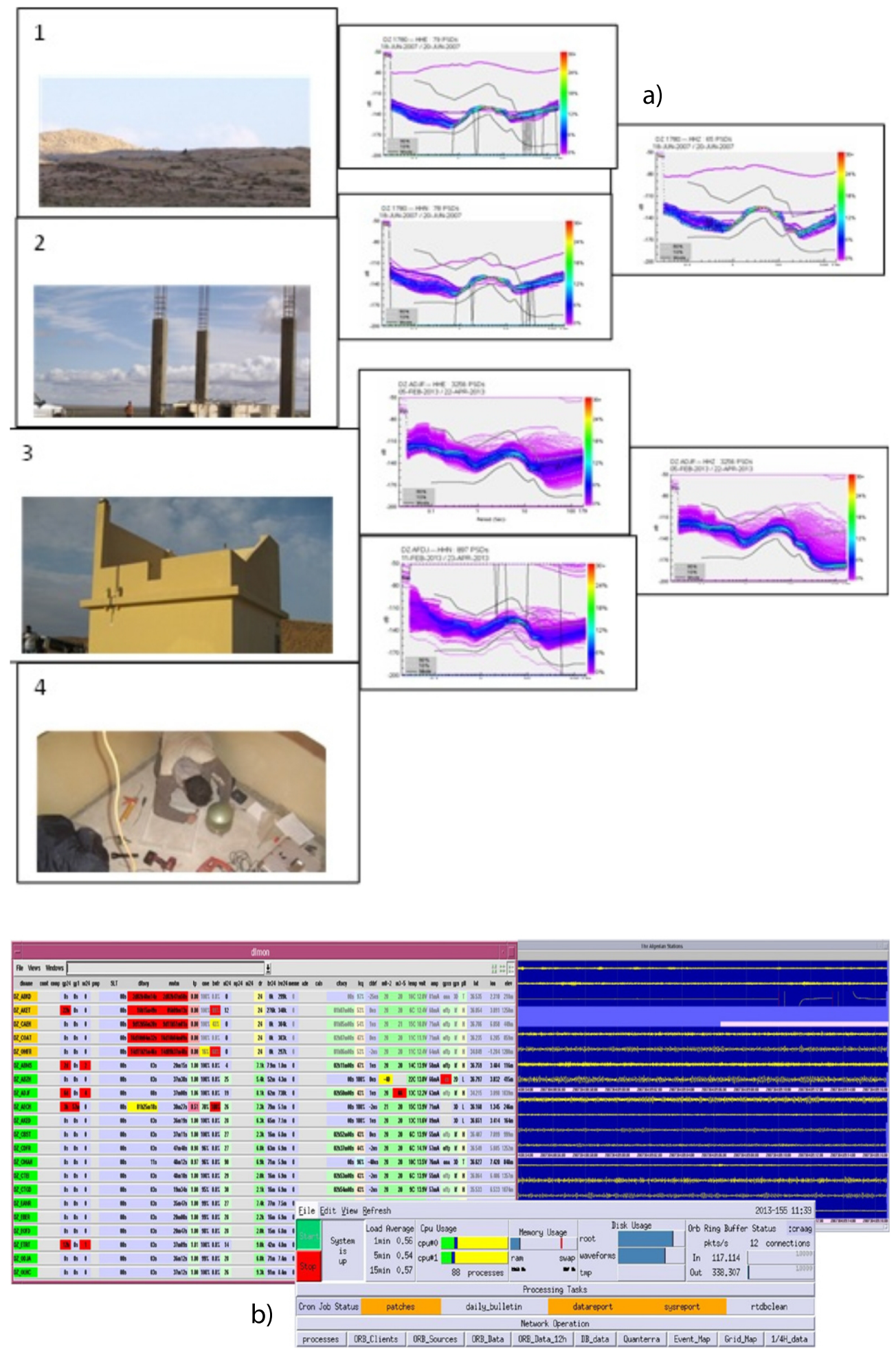

Fig. 3. (a) Data Quality tests using PQLx in different phases of station installation. 1 Site selection 2 Site building 3 Station ended. 4 After several weeks in operation. (b) State of health (dlmon) and rate of operation. 


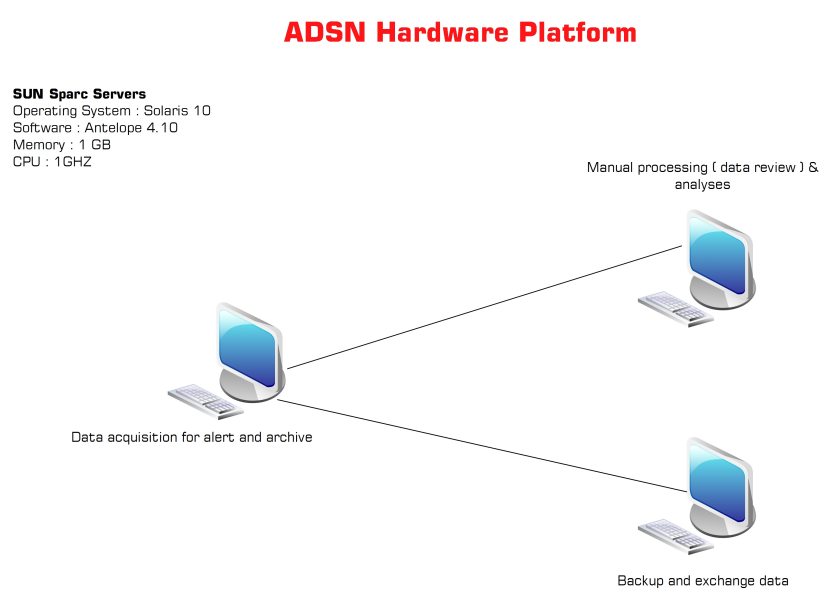

Fig. 4. The Current Hardware Plateform with the SUN Sparc Stations.

In the next phase, new stations will be installed in the western part of the High Plateaus (Fig. 2), which at present remains poorly covered.

\section{Performance of the network}

\subsection{Broadband data quality analysis}

The quality of data, particularly from the broadband stations of the new network, is the main concern and interest of the technical staff of ADSN. Indeed, the quality of the data from broadband stations is continuously controlled in quasi-realtime using "PQLX" (Pascal Quick Look eXtended) software (McNamara, 2009) to compute the PDFs (Probability Density Function) and PSDs (Power Spectral Density) of the recordings at different stages of installation and during the operation of the stations (Fig. 3a). PQLX is used to analyze seismic data in the frequency domain, and to estimate the noise sources. For the time being, we are still faced with the reality of noisy stations that are located mainly near urban areas. These stations commonly generate a number of ghost events.

The Antelope software and some other programs allow monitoring and maintenance of the entire electronic system. Regular checks are made of the power state of the system, the mass position of the sensors, and the environmental conditions inside the vaults (temperature, humidity, air pressure) (Fig. 3b).

The management of the Algerian Network by the Antelope software ensures real-time monitoring. The current hardware platform of the central station of the network runs with Sun SPARC software (Fig. 4). The operation of the network involves the following stages.

\subsection{Data transmission and acquisition}

The Antelope software uses two types of digitizers to record the data: Q330 made by Kinemetrics, and EDAS IP24, of Chinese manufacture. All the stations are connected in real time using various modes of transmission.

The ADSN seismic database contains continuous data that is generated at the rate of approximately 2.5 GB per day, including broadband, short period, and strong motion data. The raw data are available in miniseed format, and are archived by the Antelope system during real-time acquisition. The data can be exported indifferent formats such as ASCII, SAC, Cd1.

The number of events recorded by the network has increased significantly since the network was first installed. Indeed, before installation of the ADSN network, an average of 30 events per month was recorded. Today, the number is around 80 to 100 per month. This is due to the number and types of stations installed during this period, and their spatial distribution that enables coverage of most of the seismogenic zones of northern Algeria. Some seismic events in the southern part of Algeria, inside the Hoggar shield, have also been recorded for the first time by the network, and this demonstrates the seismic character of that region, previously thought to be aseismic.

\subsection{Realtime data analysis and alert phase}

This phase of the network performance is achieved in real time using automatic processing (Fig. 5), and the outputs include P-wave picking, event localization, determination of magnitude $\mathrm{Ml}$ or $\mathrm{Mb}$, creation of a web page, and distribution of e-mail/SMS alerts (in less than 5minutes).After the automatic picking of the $\mathrm{P}$ wave on the records of several stations in the network, the orbdetect program of Antelope is triggered to bring the records together, locate the event, and calculate different type of magnitude (Ml, Mb). The earthquake is then recorded in the database with its parameters (Latitude, Longitude, Origin time, Magnitude, Depth).

After the automatic detection of an earthquake, an alert is triggered, and users are notified with SMS and emails within 5 min (Fig. 6).

We note that the number of stations involved in the location of any event is critical for the quality of the alert. In general, the records from at least five stations are needed to provide a correct location for a seismic event(see Table 1). When using records from fewer than five stations, ghost events may be announced by the system, and this may be a consequence of the noise that is present at some stations.

\subsection{Manual processing and archiving of data}

The manual processing (Fig. 7) of the seismic events is done mainly to check, after the alert message has been sent, that the automatic phase picking has shown a precise hypocenter 


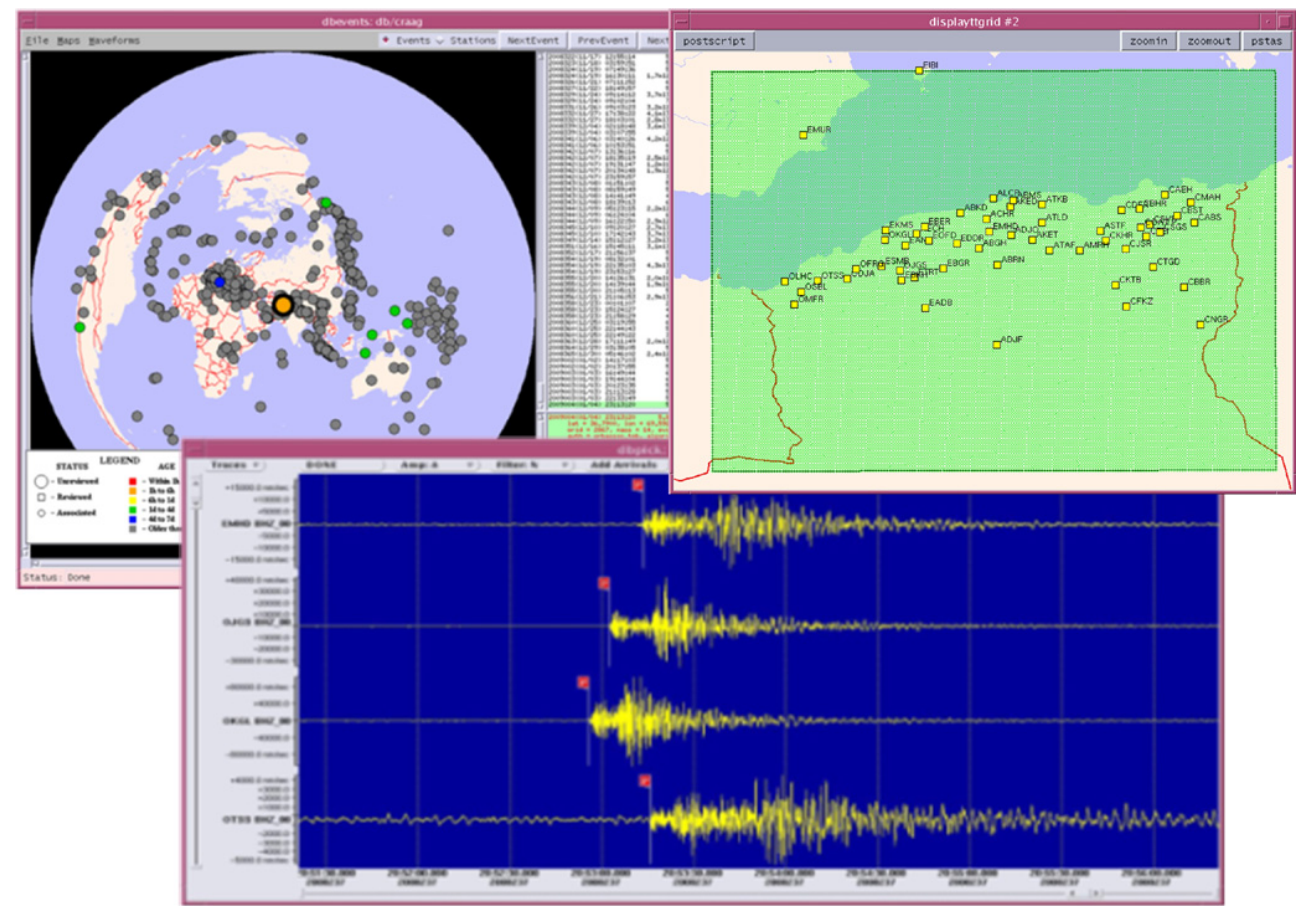

Fig. 5. Automatic processing using different screens for editing the signal, the network and the location in the region.

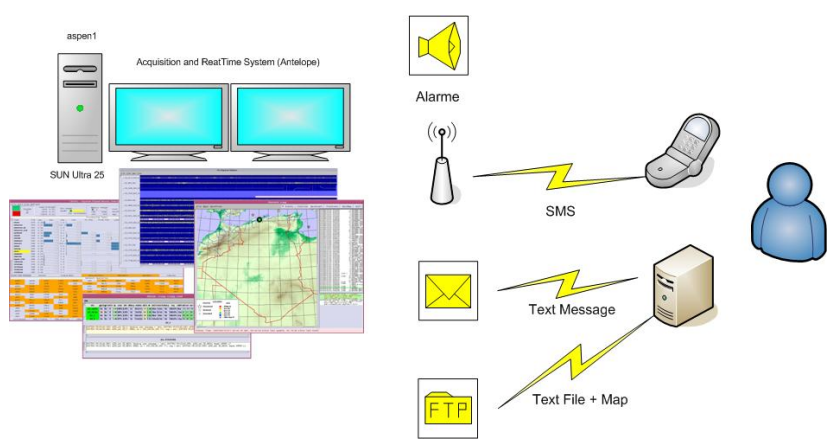

Fig. 6. Transmission of the alert messages from the Seismic Network Center to the users.

location and magnitude for the seismic event. The event is then entered into the database, and the data used to create reports or bulletins for each earthquake. After the event has been analyzed, the next step consists of introducing separate archives of the waveforms in the RAID (internal disk) and external disk.

\subsection{Data exchange}

The data are exchanged with some neighboring countries (Spain, Tunisia, Marocco) that have different protocols (Fig. 8). In other hand, international standards allow the Algerian data to make a contribution to seismic monitoring in the Mediterranean (CSEM) or now ISC. We also note that
Table 1. Statistics of the correct location of the Alert system.

\begin{tabular}{lll}
\hline $\begin{array}{l}\text { Number of } \\
\text { stations }\end{array}$ & $\begin{array}{l}\text { Average magnitude } \\
\text { detected }\end{array}$ & $\begin{array}{l}\text { Percentage of } \\
\text { correct locations }\end{array}$ \\
\hline 3 stations & $M<1$ & $30 \%$ \\
4 stations & $1.2<M<2$ & $60 \%$ \\
5 stations & $1.6<M<2.5$ & $90 \%$ \\
6 stations & $M>2.5$ & $100 \%$ \\
\hline
\end{tabular}

CRAAG contributes with one station "DZ-OKGL" to the ORFEUS VEBSN.

\subsection{Current developments and future work}

The present phase in developing the performance of the network involves improving its ability to assess focal mechanisms, producing the shakemap, a seismic web monitoring system using a balanced scorecard (BSC), and improving the webpage service for users. In addition, 70 GPS receivers have been located alongside seismological stations to know more about the deformation and earthquake rupture processes.

The next two years will see the acquisition of new broadband stations, helping us to increase the density of the network in northern Algeria. We also expect to install some broadband stations in southern Algeria around the Hoggar shield (one station is already installed in the Tamanrasset $\mathrm{Ob}$ servatory). 


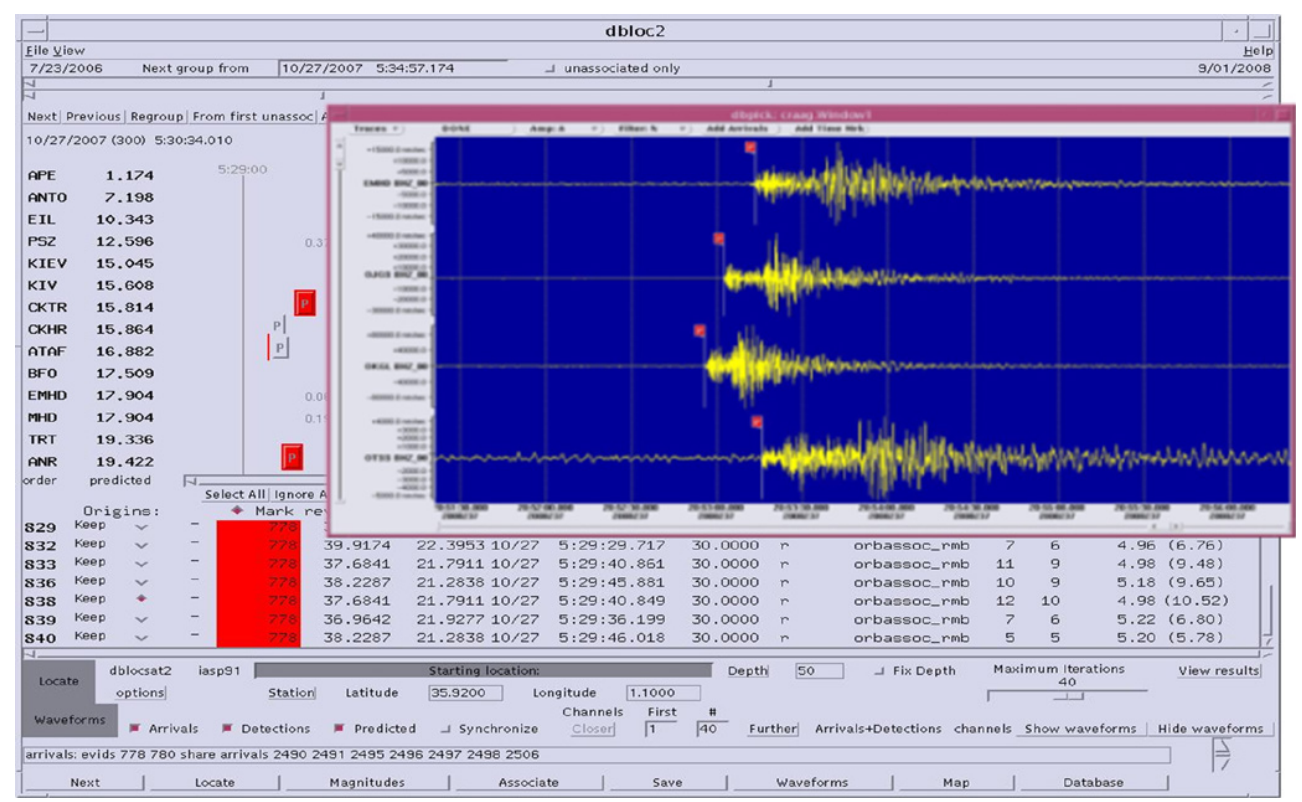

Fig. 7. Manual processing with Antelope reviewing the different parameters of the seismic event.

\section{Data Exchange}

Available protocol to exchange data

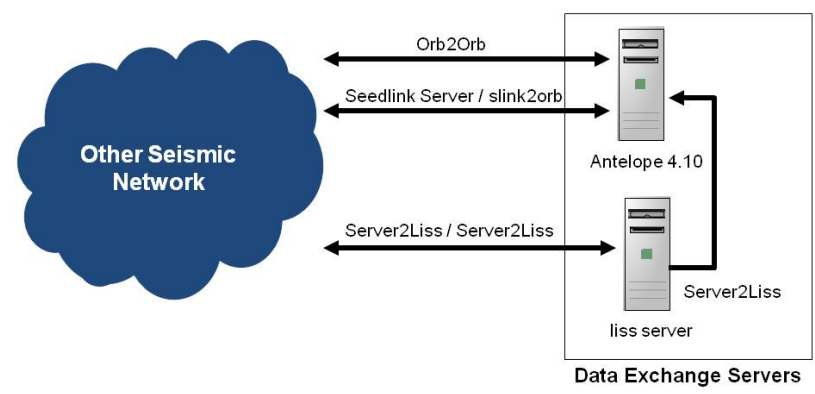

Fig. 8. Data exchange with other Data Centers.

\section{Conclusions}

The new Algerian Digital Seismological Network (ADSN) has drastically improved seismic monitoring in Algeria. First, it provides a large amount of continuously recorded high-quality waveform data, it gives new insights into Algerian seismic activity, and it allows us to determine more accurately the different parameters of each seismic event (magnitude, focal mechanism, depth). In summary, the new network provides an excellent tool for seismic studies and crustal investigations. In addition, the new network means that Algeria is now equipped with a seismic warning system, and this aids the management of a seismic crisis by distributing information about the seismic event in the first few minutes, and keeping the various stakeholders informed (authorities, media, population).
In the near future, the network will be improved by the installation of around 50 new stations with various type of seismological and geodetic instruments. These will enhance the performance of the network and help us in our development of an early warning system for Algeria.

Finally, it is clear that the ADSN will play a key role in helping the authorities to mitigate seismic risk in Algeria.

Acknowledgements. The authors would like to thank all engineers and technicians of the CRAAG stations who participate in installation of the network. The authors are deeply grateful to algerian authorities and especially the Interior Ministry for their help and financial support in this project. Finally, we would like to thank the Editor and the reviewers for their assistance and helpful comments.

\section{References}

Allen, R. M.: The ElarmS Earthquake Early Warning Methodology and Application across California, in: Earthquake Early Warning Systems, edited by: Gasparini, P. et al., 21-41, Berlin, Springer, 2007.

Benhallou, H.: Les catastrophes sismiques de la région d'Echellef dans le contexte de la sismicité historique de l'Algérie. Thèse d'Etat. USTHB, Alger, 294 pp., 1985.

Erdik, M.; Fahjan, Y., Ozel, O., Alcik, H., Mert, A., and Gul, M.: Istanbul Earthquake Rapid Response and the Early Warning System, B. Earthq. Eng., 1, 157-163., 2003.

Glangeaud, A.: Les séismes d'Algérie de 1940 à 1950 inclus, Annales de l'Institut de Physique du Globe de Strasbourg, TVII, 3, $1-23,1954$.

Hee, A.: Catalogue des séismes algériens de 1850 à 1911, Ann de l'IPG de Strasbourg, t VI, 41-49, Strasbourg, 1950. 
McNamara, D. E., Hutt, C. R., Gee, L. S., Benz, H. M., and Buland, R. P.: A Method to establish seismic noise, Baselines for Automated Station Assessment, Seismol. Res. Lett., 80, 628-637, 2009.

Mokrane, A., Ait Messaoud, A., Sebai, A., Menia, A., Ayadi, A., and Bezzeghoud, M.: Les séismes en Algérie de 1365 à 1992, Catalogue CRAAG (Centre de Recherche en Astronomie Astrophysique et Géophysique), Alger, 277 pp., 1994.

Nakamura, Y.: Research and Development of Intelligent Earthquake Disaster Prevention System UrEDAS and HERA, Journal of Structural Mechanics and Earthquake Engineering, Japan Society of civil engineers, No. 531/I-34, 1-33, 1996.

Rothé, J. P.: Les séismes de Kherrata et la sismicité de l'Algérie, Bull. Serv. Carte Geol. Algerie, Geophys., 3, 3-40. 1950.

Roussel, J.: L'activité sismique en Algérie de 1951 à 1970 inclus. Extrait du Bulletin de la Société d'histoire naturelle de l'Afrique duNord, tome 64, fasicule 3 et 4, 211-228, 1973.
Yelles-Chaouche, A. K., Haned, S., and Deramchi, A.: The CRAAG, Algeria, CSEM Letter, No. 20, September 2003.

Yelles-Chaouche, A. K., Boudiaf, A., Djellit, H., and Bracene, R.: La tectonique active de la région nord-algérienne, C.R. Geosci., 338, 126-139, 2006.

Yelles-Chaouche, A. K., Djellit, H., Haned, S., Deramchi, A., Allili, T., Kherroubi, A., Beldjoudi, H., Semmane, F., Amrani, A., Haddana, Z., Chaoui, F., Aidi, A., and Allili A.: The Algerian Digital Network, CSEM Letter, No 22, May, 2007.

Yelles-Chaouche, A. K., Djellit, H., Allili,T., Semmane, F., Beldjoudi, H., Kherroubi, A., Haned, A., Aidi, C., Alili, A., Haned, S., and Deramchi, A.: The Algerian Seismic Network: Recent Development European Seismological Congress, Moscow, 2012. 